\title{
Autopsia social de un subtierro ${ }^{1}$ A Social Autopsy of Mass Grave Exhumations in Spain

\author{
FRANCISCO FERRÁNDIZ \\ Centro de Ciencias Humanas y Sociales, CSIC \\ francisco.ferrandiz@cchs.csic.es
}

RESUMEN. Este artículo propone una conceptualización de las fosas comunes de la derrota derivadas de la Guerra Civil española (19361939) y la posguerra utilizando la noción del subtierro - asimilable a una forma extrema de exilio interior bajo tierra - , cuyo origen histórico sería el mismo que el de los exiliados, desterrados o transterrados que tuvieron que abandonar España, pero cuyas condiciones de producción y cuya historia social, política, simbólica y judicial desde la guerra hasta el presente tiene características específicas. A partir de ahí, una vez definidos los cuerpos que se encuentran en estas fosas y el tipo de violencia que se inscribió sobre ellos, se realiza una autopsia social de su evolución histórica y del recorrido que su apertura desde el año 2000 está teniendo en la sociedad española contemporánea desde el punto de vista político, judicial, científico, mediático y asociativo.

Palabras clave: España, Guerra Civil, antropología del cuerpo, antropología de la violencia, memoria social, fosas comunes, exhumaciones, derechos humanos.
ABSTRACT. This paper proposes a conceptualization of the mass graves of defeat, mostly derived from the Spanish Civil War (19361939) and the early Postwar years, understanding them as a radical form of a below ground internal exile. Once the bodies in the mass graves and the violence inscribed in them have been characterized, the paper engages in a social autopsy of how this memory has evolved in contemporary Spain since the year 2000, when the first exhumation of the most recent cycle of Civil War graves took place. The analysis follows the political, judicial, scientific, media and associative impact of these exhumed bodies.

Key words: Spain, Civil War, anthropology of the body, anthropology of violence, social memory, mass graves, exhumations, human rights.

1 Quiero agradecer las sugerencias de José Antonio Zamora y Antolín Sánchez Cuervo a la hora de diseñar este texto. En el primer caso, sobre el Benjamin subterráneo y, en el segundo, sobre exilios, destierros y transtierros. Este artículo forma parte del proyecto $\mathrm{I}+\mathrm{D}+\mathrm{i} L a s$ políticas de la memoria: Análisis del impacto de las exhumaciones de la Guerra Civil en los primeros años del siglo XXI (MICINN, CSO2009-09681). 
(...) ¡Cuántas cosas no fueron allí enterradas y sacrificadas entre conjuros y ensalmos! ¡Qué siniestro gabinete de curiosidades aparece allí abajo, donde las zanjas más profundas se hallan reservadas a lo más cotidiano! Una noche de desesperación me vi, en sueños, renovando impetuosos lazos de amistad y fraternidad con el primer compañero de mis tiempos de colegial, a quien llevaba sin ver varios decenios y apenas había recordado en todo ese tiempo. Al despertar, sin embargo, lo vi claro: aquello que la desesperación, como una carga explosiva, había sacado a la luz, era el cadáver de ese hombre que estaba allí emparedado, y debía impedir que quien viviera allí alguna vez, pudiera asemejársele en algo.

Walter Benjamin, «Subterráneo», Calle de dirección única

\section{Subterrados}

La noción de subtierro que se usa en este texto pretende profundizar el campo semántico de la experiencia de la derrota en la Guerra Civil española, poniendo el énfasis en el perfil histórico, social, político y simbólico de las decenas de miles de personas que fueron ejecutadas en la retaguardia del ejército sublevado durante la Guerra Civil (1936-1939) y, posteriormente, en la posguerra franquista, y acabaron amontonadas en fosas comunes a lo largo de toda la geografía del país. La apertura contemporánea de estas fosas comunes y la exposición pública y muy explícita de los cadáveres que contienen en el contexto de la sociedad de la información y el conocimiento (Castells 2000), ajena al momento histórico en el que se produjeron las ejecuciones, están forzando al país a confrontarse de manera atormentada con una modalidad de víctimas de violencia represiva que, puede argumentarse, tras formar parte del anclaje justificador de la dictadura franquista, habían quedado también huérfanas de legitimidad y reconocimiento durante al transición y la propia democracia en España. La condición del subtierro, por lo tanto, se referiría a un tipo de éxodo bajo tierra, quizá a una forma extrema de exilio interior, cuyo origen histórico sería el mismo que el de los exiliados, desterrados o transterrados que tuvieron que abandonar España (Gaos 1953; Monclús 1989), pero cuyas condiciones de producción y cuya historia social, política, simbólica y judicial tiene características específicas. En concreto, su relación con una experiencia de muerte violenta en el contexto de una política de exterminio del adversario, y el paso sucesivo de regímenes de olvido social sobre el conjunto de cadáveres que fueron sembrados de manera ejemplarizante por todo el país en fosas comunes.

Las fosas que se están abriendo en la España contemporánea son en su mayoría enterramientos irregulares derivados de lo que destacados historiadores han caracterizado como furia exterminadora de acciones coordinadas de limpieza de la retaguardia del ejército sublevado, prolongada después durante la dictadura (Juliá 1999, 19; Casanova 2002). La historiografía de los últimos años, tanto la escrita en España como en el extranjero, ha dado pasos muy importantes en la documentación y análisis de la multiplicidad de vio- 
lencias que se solaparon durante la Guerra Civil y la postguerra, en la que hubo menos mortalidad en los frentes de batalla que en las acciones represivas (Rodrigo 2008, 25). Más en concreto, ha permitido cartografiar mejor la naturaleza y escala de las maquinarias exterminadoras de retaguardia en ambos bandos, así como su evolución, sus modalidades y sus variantes regionales. Frente a las tesis del equilibrio represor y la locura trágica de las dos Españas autores como Casanova (2002), Rodrigo (2008, 21-29), Preston (2011) y otros han señalado las asimetrías entre unas estructuras y dinámicas de violencia de retaguardia y otras. Santos Juliá, por ejemplo, en prólogo al influyente libro Victimas de la guerra civil, establecía que, como ya demostraba la historiografía disponible hasta la fecha, mientras que «en la zona insurgente, la represión y la muerte tenían que ver con la construcción de un nuevo poder», las grandes matanzas de la República «ocurrieron como resultado del hundimiento del Estado y remitieron a medida que el Estado se reconstruía» (1999, 25-27; Rodrigo 2008, 31-49; Preston 2011, 17-26).

Según esta corriente historiográfica crítica, las fosas comunes que luego serían las de los derrotados en la guerra son parte crucial de una inversión en terror asociada a una pedagogía de la sangre planificada y ya escenificada en las guerras coloniales en Marruecos (Rodrigo 2008; Preston 2011, 615-669), que fue clave en la estrategia militar del ejército sublevado en las retaguardias que iba controlando. Como lugares de memoria ejemplarizante o memoriales del miedo, las fosas comunes de la derrota contribuyeron con su presencia en el paisaje no sólo físico sino político, simbólico y social a consolidar las raíces del régimen dictatorial que se implantó en el país tras la guerra bajo el gobierno del general Francisco Franco. Esta inversión bélica en terror, prolongada en más ejecuciones, presidios, trabajos forzados, depuraciones, humillaciones públicas y otras modalidades represivas tras el fin del la guerra, cobró sin duda sus frutos en la dictadura, aunque su amargo patrimonio evolucionó y se transformó con el propio régimen franquista, disminuyendo paulatinamente su eficacia originaria a medida que el amplio y heterogéneo cuerpo social de los derrotados en la contienda absorbía el golpe. Aún así, como demuestra el rebrote contemporáneo del debate nacional e internacional sobre guerra, franquismo y represión, las heridas que dejaron en el cuerpo social y político fueron muy profundas y atravesaron generaciones.

Estas diferencias entre las violencias de retaguardia, muy condicionadas por el devenir de la guerra, tienen una correlación directa con las políticas de propaganda y memoria de la contienda que se instauraron durante el franquismo. Es éste un tema de mucha complejidad en el que no entraremos aquí (Box 2010; Aguilar 2008; Molinero 2005). Para lo que nos interesa en este texto, la gestión histórica de los cadáveres de la guerra, no puede obviarse la creación en el país de dos espacios de muerte claramente diferenciados (Taussig 1987) en el que los cuerpos asumidos como propios por los vencedores - sobre los que se legisló, se fijaron pautas de rescate y reinhumación, 
se construyó un relato heroico y martirial y se establecieron diversas modalidades de visibilización, homenaje y dignificación-, tuvieron desde el primer momento un tratamiento radicalmente diferenciado del de los cadáveres de los vencidos - que, por un lado ejemplarizadores del destino de la disidencia y, por otro, abandonados a su suerte, comienzan una larga travesía de subtierro que ha durado varias décadas.

Aunque el BOE recoge otras iniciativas que demuestran cómo el bando atribuido al cadáver fue determinante en su tratamiento legal y político, veremos sólo un ejemplo ilustrativo de su expresión en la legislación funeraria. En julio de 1946, una vez confirmado que el Valle de los Caídos — destino final de los «restos sagrados de los mártires de la Cruzada» ${ }^{2}$ - , tardaría bastante tiempo en construirse, el gobierno se vio obligado a modificar una disposición funeraria previa que obligaba al entierro definitivo de los cadáveres a los diez años de su muerte, a medida que empezaba a afectar a los primeros fallecidos tras el levantamiento militar de 1936. Para ello, se promulgó en el BOE una orden, «por la que se prorrogan indefinidamente los enterramientos temporales de los restos de los caídos en nuestra Guerra de Liberación», hasta que estuviera lista la cripta del Valle para darles «digna sepultura». Siempre y cuando «se trate de enterramientos de restos de caídos tanto si perecieron en las filas del Ejército Nacional como si sucumbieron asesinados o ejecutados por las hordas marxistas en el período comprendido entre el 18 de julio de 1936 y el $1 .^{\circ}$ de abril de 1939, o aún en fecha posterior, en el caso de que la defunción fuera consecuencia directa de heridas de guerra y sufrimientos de prisión» ${ }^{3}$. Quedaba suficientemente claro que los cuerpos sobre los que se legislaba eran exclusivamente los de los caídos, héroes y mártires de la Cruzada, colocando así en el limbo de los excluidos de la legislación funeraria, y en consecuencia de la comunidad legítima de los muertos, a los cadáveres republicanos y, por extensión, a las fosas comunes que los contenían.

Esta política respecto a las víctimas genuinas de la guerra tiene a su vez correlación con las prácticas y políticas de exhumación de cadáveres del conflicto que se establecieron en el país tras la guerra. En otros textos anteriores (Ferrándiz 2009) he destacado la importancia de entender las exhumaciones contemporáneas en perspectiva histórica, es decir, como el episodio más reciente de diferentes secuencias exhumadoras de la guerra. De manera esquemática, los ciclos de desentierro y reinhumación que se han sucedido (y solapado en casos) en España incluyen en un primer momento el proyecto de rescate y dignificación generalizada - aunque en ningún caso completa, por las enormes dimensiones de la guerra, la gran mortandad y las dificultades de organización del Estado- de héroes y mártires del bando vencedor en la posguerra, con todo el aval oficial de la dictadura, procedimientos adminis-

\footnotetext{
2 Véase el BOE de 5 de abril de 1940, p. 2320.

3 BOE núm. 196, de 15 de julio de 1946.
} 
trativos ad hoc y una ritualización y relato legitimadores de corte nacionalcatólico (Aguilar 2008; Box 2010); el arrastre político, administrativo y simbólico de más de 30.000 cuerpos hacia el Valle de los Caídos desde finales de los años cincuenta (Olmeda 2009; Solé 2009; Ferrándiz 2011); o las excavaciones de las fosas republicanas del siglo XX — clandestinas y dispersas durante el franquismo, familiares, locales, carentes de apoyo técnico y escasamente mediáticas durante la transición y democracia-. Las fosas que se están abriendo en el siglo XXI añaden un nuevo poso de exhumación y reinhumación sobre los cadáveres de la guerra, que esta vez se enfoca de manera decisiva en un numeroso colectivo de cuerpos mal enterrados: las personas ejecutadas en la retaguardia del ejército sublevado y durante los primeros años de postguerra.

\section{Cuerpos desvelados: autopsia social}

La obra de Walter Benjamin es un punto de fuga básico para entender la relación dialéctica entre el pasado y el presente en la modernidad. En su propuesta epistemológica, el conocimiento histórico que es preciso para producir una conciencia crítica sobre el presente no proviene del los grandes hitos de la historia de los vencedores sino de las ruinas y fragmentos, los deshechos que se encuentra enterrados, ocultos, o semiolvidados en los intersticios de la cultura (Buck-Morss 1991, x-xi; Zamora 2008, 110-111). Para Benjamin, son precisamente los vestigios de los oprimidos o los vencidos los que demuestran que el estado de emergencia no es la excepción sino la regla en la sociedad y cultura industriales y, por extensión en la sociedad de la información (Benjamin 2005, tesis VIII; Agamben 2004). En este contexto, la irrupción imprevista de los subterrados en la contemporaneidad, en su condición de residuos marginales de los relatos hegemónicos, como parte de las ruinas que el progreso deja a su paso, como esquirlas de una memoria que brilla repentinamente como un relámpago en un momento de peligro, como parte de la visión catastrofista del ángel de la historia benjaminiano ${ }^{4}$, convierte a sus esqueletos heridos en un fermento básico para la reinterpretación crítica del proceso histórico del último siglo en España. Por un lado, desde el corazón de la represión y, por otro, desde la periferia de la conciencia histórica de la guerra.

En el siglo XXI, la oscuridad o penumbra en la que transitaron los años estos cadáveres, desafiando el olvido en los intersticios de la modernización, ha dado paso a un régimen de visibilidad y presencia pública impensable hace unos años, en un tránsito repentino de fantasmas a cadáveres de la guerra. Diversos autores contemporáneos han usado las metáforas y creencias en los fantasmas para referirse a los recuerdos traumáticos que quedan atrapados en

\footnotetext{
4 Tesis IX (Benjamin, 2005; Mate 2009, 155-167).
} 
contextos sociales impregnados por un pasado violento sin resolver (Gordon 1997; Ferrándiz 2006; Kwon 2008). Gordon, por ejemplo, destaca la importancia del análisis de las persecuciones obsesivas por parte de fantasmas o espectros (haunting) para la comprensión de la vida social, en el plano individual y también en el colectivo. La tensión social originada por los fantasmas del pasado «no es ni una superstición premoderna ni una psicosis individual, sino un fenómeno social generalizado de gran importancia» que produce efectos bien patentes. La tensión e incertidumbre provocadas en la sociedad por este tipo de acoso son una poderosa «forma de conocimiento» que ofrece un espacio privilegiado de análisis sobre la relación entre «poder, conocimiento y experiencia» (1997:7-23). En el caso de los entierros masivos derivados de conflictos bélicos, la confusión intencionada de cuerpos no identificados en fosas sin nombre tiene el potencial para inyectar desorden, ansiedad y división en el tejido social durante décadas, como es el caso español (Robben 2000). Desasosiego social y simbólico ante la muerte masiva que se expresa en diferentes tipos de personajes y retóricas de memoria y duelo según el contexto cultural, social, político o histórico —espectros, apariciones, sucesos paranormales - , como demuestran por ejemplo el estudio de Winter sobre el rebrote de creencias en los fantasmas de los soldados tras la primera guerra mundial (1995) o el trabajo de Kwon, que analiza las creencias populares relacionadas con las fosas comunes y exhumaciones de la guerra de Vietnam.

Hemos visto como exhumaciones como las que se están haciendo en España son el resultado del tratamiento histórico injusto e indebido de determinados colectivos de muertos, sobre los que ha habido una dejación funeraria, simbólica, judicial, política y social durante décadas, pero que no han llegado a perder una presencia fantasmagórica crítica en los márgenes de la conciencia histórica del país. La aparición física repentina de estos cuerpos violentados hace seis o siete décadas, amontonados en fosas comunes - hoy artefactos averiados de la maquinaria del terror del ejército sublevado y luego del franquismo (Ferrándiz 2009, 84) - como en el aforismo «Subterráneo» que encabeza el texto, desencadenan en su despertar una cartografía paralela de peligros contemporáneos (Benjamin 2005; Zamora 2008; Mate 2009; Buck-Morss 1991, 253-262). Es en ese sentido que los cadáveres de las fosas pueden entenderse como cuerpos desvelados, en tres variantes: desasosiego subterráneo por la inatención política y funeraria de décadas, por la mala muerte y el mal entierro; inquietud social ante su estatus, también durante décadas, de secreto público, especialmente en el ámbito rural - que regresa hoy como postmemoria en la generación de nietos 5 - ; y controversia y zozobra por el proceso de desciframiento - y tam-

5 Postmemoria en el sentido de Marianne Hirsh (2008, 106), es decir, de una estructura de transmisión de conocimientos y experiencias traumáticas inter y transgeneracionalmente. 
bién reencriptación — que se pone en marcha con su salida contemporánea a la luz pública.

He argumentado que el sembrado de fosas por la geografía nacional tenía una intencionalidad paralizante a través de producción y circulación de miedo y terror por el tejido social y político. El hecho de que estas fosas generen polémica, desasosiego y desvelo en la sociedad española actual, su capacidad entrópica, confirma su eficacia incluso muy a largo plazo, aunque su significación y la intensidad de su incidencia en el tejido social, especialmente en los ámbitos rurales, ha variado de forma muy sustancial con el tiempo. Más allá de la historia de las exhumaciones derivadas de la Guerra Civil que se ha mencionado brevemente, la significación y el estatus de las fosas de la derrota - que son mayoría entre las fosas de retaguardia que aún permanecen desatendidas en todo el Estado- no pararon el reloj cuando se apagó el eco de los disparos y las abandonaron los perpetradores. Como herencia subterrada, como parte de la sombra de la República que acompañó siempre de forma crítica al franquismo (Mate 2009, 22), las fosas nunca han sido objetos inertes sino procesos complejos que se han ido «impregnando» paulatinamente con los «sucesivos presentes» (Iniesta 2009, 478). Así, se han transformado junto con el país en el que fueron implantadas, los regímenes y culturas políticas que se han sucedido, o la legislación penal, arqueológica, patrimonial o funeraria que las ha ido esquivando (González-Ruibal, 2007) ${ }^{6}$. A medida que han muerto testigos, se han modificado los paisajes, se han trasladado y remodelado cementerios y se han desarrollado las infraestructuras (especialmente las carreteras, cuyas obras de ampliación han borrado multitud de cunetas), las personas que fueron ejecutadas y arrojadas a las fosas comunes permanecieron sin apenas tutela en una secuencia de abandonos acumulada sobre los mismos cadáveres, no sólo durante la dictadura sino también hasta bien entrada la democracia.

En la última década ha habido un cambio drástico respecto a las políticas de la muerte durante la guerra y después. Las historias de ejecución y crimen que revelan estas exhumaciones y sus rutas contemporáneas de despliegue desde el subtierro hasta el ciberespacio, que esbozaremos más adelante, las han colocado en un lugar preeminente de la memoria de la Guerra Civil, entendida como un sistema nervioso. La metáfora de Taussig del sistema nervioso (1992, 1-10), derivada en parte de su interpretación del pensamiento de Benjamin, permite concebir la presencia del pasado traumático en la conciencia histórica contemporánea como una red de terminales sinápticas altamente sensibles que incluye, en el caso de la Guerra Civil española, desde relatos historiográficos a lugares de memoria, museos, exposiciones, monumentos, himnos, homenajes, archivos, piezas artísticas, álbumes u objetos personales

${ }^{6}$ Véase por ejemplo la conocida viñeta de Eneko sobre la historia de España, publicada en 20 minutos el 21-11-2008 (http://www.20minutos.es/vineta/eneko/1101/0/). 
(Nora 1989). Cuando estas terminales sinápticas conectan con fosas, el impulso nervioso que generan disemina por el tejido social, en sus ramificaciones múltiples y con diferentes grados de aceleración, desde la información más dura sobre la represión (evidencias de torturas, malnutrición, heridas de bala) hasta los objetos de profunda significación personal que aparecen en ellas o las emociones que aún tienen dificultades para expresarse.

Pero los tiempos han cambiado drásticamente. A los cadáveres exhumados de las fosas comunes en el siglo XXI no les espera ya, lógicamente, un país dominado por una dictadura con un relato hegemónico nacionalcatólico, ni siquiera por la condición menos autárquica y claustrofóbica de las fases de desarrollismo tecnocrático o tardofranquista de la dictadura (Casanova 2002, 14-17). Tampoco quedarán impregnados por las culturas políticas y dispositivos de comunicación de la transición a la democracia, ni de los primeros veinticinco años de democracia. Hijos del siglo XXI, estos cadáveres excepcionales rescatados in extremis de las tinieblas e intersticios de la historia se enfrentan más bien a una modernidad tardía de escala planetaria, una modernidad globalizada que muchos autores califican en términos de interconexión, interdependencia, colapso del tiempo y el espacio, cosmopolitismo, desterritorialización, aceleración, vértigo, simulacro o saturación de la experiencia (Harvey 1989; Baudrillard, 1991; Watts 1992; Castells 2000; Zamora 2008).

En otras palabras, su salida a la luz pública está determinada por un anacronismo radical entre las condiciones de vida y muerte en la guerra y la postguerra y una sociedad profundamente transformada por los procesos globalizadores y las sucesivas revoluciones tecnológicas. La misma transformación y aceleración o emergencia crónica de la experiencia que afecta a los habitantes de esta modernidad tardía, atañe a los cadáveres del pasado que irrumpen en ese mismo tejido social. Así, los cuerpos fusilados reaparecen de manera dramática y espectacular en la sociedad de la información y del conocimiento, profundamente condicionados en su aparición y circulación -no sólo en el ámbito del estado-nación sino también, y de forma simultánea, en el ámbito transnacional - por los dispositivos de visualización y difusión de los entornos digitales, por la proliferación de medios de comunicación y las redes sociales, especialmente a partir de la segunda parte de la década. Los cuerpos de las fosas emergen de su largo subtierro en un régimen biopolítico que Mbembe, elaborando la formulación clásica de Foucault para analizar las sombras que el ejercicio del poder proyecta sobre la muerte, la guerra, los cuerpos heridos y ejecutados, etcétera, denominó necropolítico (2003). Aunque su reflexión se dirige a las nuevas tecnologías de necropoder y destrucción en el África contemporánea, Mbembe sugiere que la generalidad indiferenciada de los depósitos de esqueletos, como ocurre también con las fosas comunes derivadas de la Guerra Civil, «provoca una tensión entre la petrificación de los huesos y su extraña frialdad», y su cualidad insumisa de «significar algo» más allá de un «estupor cruel» (Ibid., 35). En este contexto, sostie- 
nen algunos autores, el desarrollo de las ciencias de la memoria ha fomentado la colonización del recuerdo, del trauma, del sufrimiento social y sus múltiples soportes mediante diversas modalidades de conocimiento experto y prácticas terapéuticas o humanitarias (Hacking 1996; Fassin y Retchman 2009).

Así, los cuerpos ejecutados de las fosas salen también a la luz pública bajo los focos del expansivo discurso transnacional de los derechos humanos - del cual ya han sentido el roce en el auto de Garzón y en las reclamaciones de muchas asociaciones (Ferrándiz 2010) - y el creciente prestigio de las exhumaciones de fosas comunes como herramienta de reparación de agravios del pasado en el paradigma de la llamada justicia transicional. Son por lo tanto cadáveres inscritos de significación y muerte violenta, simultáneamente, por dos épocas inconmensurables y dos regímenes muy diferentes de fragilidad corpórea. Por un lado la impunidad de los arrestos, maltratos y ejecuciones en el momento de producción de las fosas comunes durante la guerra y después. Por otro, la potencial precariedad corpórea e iconográfica derivada de la fragmentación y pérdida de contexto de cadáveres bajo la lupa o incluso el microscopio en la sociedad de la información y el conocimiento que, el tratarse de cuerpos fusilados en las condiciones históricas descritas de guerra civil, represión y retaguardia, entran a formar parte necesariamente de los circuitos globales de circulación mediática y cibernética del sufrimiento y la barbarie (Ignatieff 1998, 15-37).

Una vez explícito el contexto actual de aparición los cadáveres desenterrados, podemos seguir ahora sus rutas de fuga desde las fosas en el marco social, político y tecnológico de la contemporaneidad. Los cadáveres subterrados que contienen las fosas se han convertido en protagonistas mudos, pero extraordinariamente significativos, del proceso de «recuperación de la memoria histórica» en la España del siglo XXI (Ferrándiz 2005; 2009). El seguimiento y análisis multisituado de su despliegue a través de diversos ámbitos de la experiencia contemporánea, desde los espacios de mayor intimidad, pasando por las prácticas políticas, jurídicas o simbólicas, hasta la esfera transnacional o el ciberespacio (Marcus 1995), permite, por reutilizar un concepto de Klinenberg (2002), llevar a cabo a una autopsia social de su impacto en la España contemporánea y, al tiempo, apuntar la ruta que están emprendiendo, más allá de las fronteras nacionales, en el catálogo transnacional de los crímenes contra la humanidad.

\section{Ultratumba: vidas más allá de la fosa común}

La aparición de los cuerpos fusilados en la España contemporánea ha desencadenado, pues, procesos muy variados y controvertidos cuyo impacto y profundidad apenas podemos comenzar a predecir. Y es que los cuerpos desente- 
rrados, tan radicalmente expresivos y necesariamente incómodos, se imbrican profundamente en su nueva sociedad de acogida, muy diferente de la sociedad que los ejecutó y abandonó a su suerte unas décadas antes, cuestionando desde silencios domésticos hasta acuerdos políticos de mucho calado. En este proceso de colapso temporal entre las políticas represivas del pasado y su exposición pública contemporánea en las exhumaciones, los cuerpos fusilados son sometidos a regímenes de discursos y tecnologías de diferente naturaleza e influencia social y, al mismo tiempo se convierten en lugares de memoria, debate y controversia para los vivos (Crossland 2009, 147). Es por lo tanto un proceso de inscripción simultánea, o impregnación recíproca, entre los cuerpos exhumados y las esferas contemporáneas por las que se despliegan.

Desglosaré esta irrupción anacrónica de cadáveres inscritos por la violencia hace ya siete décadas en una secuencia de vidas más allá de la fosa común tras la exhumación, ampliando el conocido concepto de Kathrine Verdery de la «vida política de los cadáveres». Esta autora norteamericana popularizó esta expresión para capturar las alambicadas negociaciones políticas sobre el destino de las momias, cadáveres y estatuas de próceres - y también de algunas personas desconocidas-, en Europa del Este tras el hundimiento de la Unión Soviética, como por ejemplo los debates sobre el destino de la momia de Lenin en Rusia o la importancia política de la repatriación del esqueleto de Béla Bartók en 1988 a Hungría o del corazón del Zar Boris III a Bulgaria en 1989, entre otros muchos (1999, 13-14). Verdery reconoce que estudiar las dimensiones políticas de la gestión postmortem de los cadáveres es un tema inmenso que tiene que comprenderse de manera transversal e interdisciplinar. En sus palabras, «hacerle una mínima justicia requiere prestar atención al simbolismo político, a los rituales y creencias funerarios - como por ejemplo las ideas de lo que es un "entierro apropiado"-, a las conexiones entre los cadáveres que están siendo tratados y los contextos nacionales e internacionales de su gestión, y a las reevaluaciones o reescrituras del pasado y la construcción y recuperación de "memoria"» (Ibid., 3). Para el caso específico que estudia, esta autora añade otras consideraciones ineludibles para la mínima comprensión: la llegada de regímenes democráticos, el desarrollo de los mercados y el regreso de la propiedad privada, el resurgir de los cultos religiosos o la creación de nuevos estados (Ibid.). Extender el análisis de los ámbitos de impacto y controversia en torno a un colectivo de cadáveres recuperados tras décadas en enterramientos inapropiados como son las fosas comunes de la derrota en España implica, como veremos a continuación, la necesidad de plantear un marco conceptual aún más amplio y diversificado que el sugerido por Verdery.

Como ocurría en el texto de conceptualización inicial de los lugares de memoria de Pierre Nora (1989), la propuesta de vidas de ultratumba de los cadáveres de las fosas comunes no se plantea como un catálogo cerrado sino que, más bien al contrario, pone las bases para un refinamiento ad infinitum 
de sus itinerarios y de los efectos que cada uno de ellos, y todos en conjunto, tienen sobre estos cuerpos reaparecidos, y viceversa. De entre las múltiples rutas de potencial despliegue contemporáneo de los fusilados, planteamos las siguientes vidas: asociativa, política, mediática, judicial, científica y emocional. Un breve recorrido por estos ámbitos de circulación de los cadáveres de las fosas en la sociedad contemporánea es suficiente para reconocer la profundidad de su huella.

El goteo a la sociedad de cuerpos exhumados en la última década fue impulsado inicialmente desde la sociedad civil. Por otro lado, ha contribuido de forma decisiva a la consolidación y creación de un movimiento social fragmentario y heterogéneo, de corte al tiempo local, autonómico y nacional, con amplias redes y ramificaciones cibernéticas que han permitido el desarrollo de una tupida red con innumerables terminales sinápticas por las que circula información y opinión, a veces de manera vertiginosa, sobre la investigación, localización, exhumación y conmemoración de los cadáveres recuperados, entre otras actividades asociadas, en el marco de una lógica cultural de la conectividad (Juris 2008, 11). Este conglomerado de asociaciones impulsado inicialmente por el debate social en torno las exhumaciones, a pesar de las polémicas y la diversidad de sensibilidades internas, genera continuamente nuevas formas de demanda y dignificación de las diversas víctimas de la represión franquista, más allá de los fusilados (Ferrándiz 2005). Su momento de mayor proyección pública, las manifestaciones del 24 de mayo de 2010 contra la impunidad del franquismo en diversas ciudades españolas, pusieron de manifiesto que aunque su anclaje es todavía local, autonómico o nacional, su potencial para movilizar contrapúblicos transnacionales a través del uso cada vez más generalizado de las nuevas tecnologías no es desdeñable (Olesen 2005). Convocadas en buena parte a través de redes sociales como Facebook, estas manifestaciones eran una respuesta de este universo asociativo ante los sucesivos obstáculos políticos, judiciales y mediáticos a la polémica pero simbólica y socialmente eficacísima traducción del derecho internacional al caso de la impunidad del franquismo que Baltasar Garzón había ofrecido a finales de 2008 a las asociaciones de víctimas y a la sociedad española en general, incluyendo la judicatura (Ferrándiz 2010).

A pesar de que no todas las asociaciones del ámbito de la «memoria histórica» que han surgido desde el años 2000 fomentan las exhumaciones ni las han colocan en el centro de su agenda reivindicativa, un buen número de ellas sí están tan influidas en su funcionamiento y estructura por la respuesta a la compleja búsqueda, aparición y gestión de los cadáveres subterrados, como lo están éstos por las retóricas, rituales y prácticas conmemorativas que las asociaciones van elaborando para su acogida y dignificación. Con desigual apoyo institucional y condicionadas por la ausencia, desarrollo, mantenimiento o declive de políticas públicas de la memoria por parte del gobierno central, las distintas autonomías o los propios municipios, su activismo en 
torno a proyectos como excavaciones, listas de víctimas y proyectos de todos los nombres, mapas de fosas, actos de devolución de los cadáveres a sus municipios, teñidos en muchas ocasiones de reivindicaciones de la Segunda República y del Frente Popular (expresada en el uso frecuente de algunos de sus símbolos como la bandera tricolor o el himno de Riego), ha ido configurando un repertorio de desagravio y reparación con variantes locales y autonómicas, pero necesariamente condicionado por la aparición de los cuerpos fusilados. La progresión del tejido asociativo articulado en torno a los cadáveres recuperados ha tenido como consecuencia el desarrollo paulatino de una cultura política que comparte un cierto sentido común de interpretación y tratamiento ritual y político de estos cuerpos, a pesar de las discrepancias entre los discursos y las prácticas de algunas de las asociaciones (Ferrándiz 2005).

Esta vida asociativa de los cadáveres está entreverada con una compleja vida política, en el sentido más restringido de Verdery. Aunque el entrelazamiento de los subterrados con acciones políticas se da a distintos niveles y hay muchos actores involucrados, aquí sólo nos referiremos con brevedad a las iniciativas políticas de corte institucional directamente relacionadas con la reaparición de los cadáveres de la derrota. Hay que recordar que el ciclo de exhumaciones del siglo XXI empezó durante el gobierno de José María Aznar, y durante ese período la implicación institucional en las exhumaciones y en su gestión se producía, si acaso, sólo en el ámbito municipal o autonómico, con políticas públicas pioneras como la del Gobierno Vasco, que comenzó en 2002 (Ferrándiz 2005) ${ }^{7}$. A partir de su victoria en las elecciones de 2004, el gobierno de Zapatero tomó la decisión de reaccionar ante la presión ejercida por las asociaciones que representan a los descendientes de los vencidos con la promulgación de una ley. Desde el año 2006, durante la discusión de esta ley, el gobierno puso en marcha una convocatoria a través de Presidencia del Gobierno que posibilitó la financiación de excavaciones y otras actividades relacionadas con ellas (pruebas de ADN, informes técnicos, monolitos, homenajes). Los duros debates parlamentarios sobre la ley fueron un canal de entrada de los cadáveres de las fosas en el debate político nacional.

La ley de memoria histórica aprobada a finales de diciembre de 2007 incluía unos apartados específicos relacionados con las exhumaciones, en concreto los artículos 11-14, que el Estado facilitaría «las actividades de indagación, localización e identificación de las personas desaparecidas violentamente durante la Guerra Civil o la represión política posterior y cuyo paradero se ignore» ${ }^{8}$. Aunque insuficiente para muchas asociaciones, era la primera vez que se legislaba directamente y de manera integral sobre estos

7 El Gobierno Vasco creó en diciembre de 2002 una Comisión Interdepartamental orientada a la localización, identificación y posible exhumación de desaparecidos durante la guerra civil en el ámbito territorial de la Comunidad Autónoma del País Vasco, presidida por el Director de Derechos Humanos que había entonces, Txema Urquijo.

8 BOE núm. 310, de 27 de diciembre de 2007, p. 53413. 
cadáveres. Pero el sistema de subcontrata elegido por el gobierno, mediante subvenciones a las asociaciones y agrupaciones de familiares para que llevaran acabo con sus medios y contactos con expertos las excavaciones, imposibilitó a la postre el establecimiento de protocolos homogéneos para la exhumación y de rituales políticos o funerarios homogéneos de reintegración de los cadáveres en la sociedad española contemporánea ${ }^{9}$.

La creación de una Oficina de Víctimas de la Guerra Civil y de la Dictadura dependiente del Ministerio de Justicia en diciembre de 2008 y la publicación posterior de un portal Web de Memoria Histórica por parte de Presidencia del Gobierno en marzo de 2011 (que incluye un mapa de fosas de escala nacional), son algunos de los desarrollos más tangibles de esta ley en relación con las exhumaciones. Por otro lado, entran en esta categoría, por acción u omisión, el conjunto de políticas públicas de memoria relacionado con los cuerpos de las fosas comunes en el nivel de las comunidades autónomas, cuya complejidad y heterogeneidad no se puede discutir aquí. Sobre el terreno, la presencia ocasional y no pautada de autoridades o líderes políticos en actos de desenterramiento y de retorno de los cadáveres a sus pueblos, que en algunos casos han cobrado forma de funerales municipales presididos por alcaldes y miembros de los consistorios, unida a la filiación y protocolos de actuación en fosas y homenajes explícitamente políticos de algunas asociaciones como el Foro por la Memoria, acaban por componer el mosaico de esta fragmentaria vida política de los cadáveres.

Compleja y controvertida está resultando también la vida judicial de los subterrados. Está relacionada con las formas en las que estos cuerpos fueron y están siendo ignorados, judicializados o esquivados por la lógica y práctica judiciales tanto en el momento de los arrestos y ejecuciones como a partir de la puesta en marcha del movimiento para la recuperación de la memoria histórica del siglo XXI y, más en concreto, del proceso de exhumaciones. Ambos tiempos y regímenes jurídicos que afectan a los cadáveres: (a) el de guerra en la zona rebelde y el de posguerra franquista, y (b), el contemporáneo, entran en tensión y contradicción, implosionan el uno en el otro en la propia excavación y en proceso de reingreso de los cadáveres en el cuerpo social y político.

En relación a la cobertura legal de los fusilamientos, tras una primera fase de terror caliente durante el verano y otoño de 1936, en la que gran parte de las ejecuciones en la retaguardia del ejército rebelde - que se calculan en torno a 30.000 - fueron extrajudiciales y derivadas de la promulgación de bandos de guerra, muchas de las personas ejecutados posteriormente en la retaguardia sublevada, de una forma más generalizada a partir de noviembre de 1937, están inscritas de origen por tribunales militares, consejos de guerra sumarísimos y condenas de muerte por delitos tales como la «adhesión a la rebelión militar» —el llamado terror legal- (Casanova 1999, 159-177). Así,

9 Véase http://www.memoriahistorica.gob.es/ 
la presencia o ausencia de juicio militar previo a la ejecución es un poso inicial que diferencia a los cadáveres de las fosas de la derrota, no sólo por el diferente estatus jurídico de la violencia de la que fueron víctimas, sino también por la existencia o no de documentación sobre su paradero actual y algunas circunstancias de la muerte.

Según la interpretación más extendida en el ámbito judicial en el país, los crímenes y ejecuciones que originaron las fosas comunes de la derrota ya fueran extrajudiciales o avalados por tribunales militares están, según el ordenamiento jurídico español actual - tal y como se expresa en el artículo 131 del Código Penal-, formalmente prescritos ${ }^{10}$. Esto explica el archivo casi generalizado que hacen los juzgados territoriales de las denuncias de familiares y asociaciones en el marco de la lógica judicial nacional. Ya hemos visto como hasta la Ley de Memoria Histórica de 2007 y el establecimiento de diversos protocolos de intervención técnica en algunas comunidades autónomas, las fosas y los cadáveres que contienen contemplaron el paso de las décadas deslizándose de manera cada vez más profunda en un limbo legal y patrimonial: más allá de la ley, más acá del patrimonio (González-Ruibal 2007). La aparición de protocolos de exhumación en algunas comunidades autónomas, heterogéneos, desiguales y dependientes de instituciones de diverso rango, han servido para ordenar las excavaciones allí donde se aplican pero no para aclarar aspectos cruciales de los cuerpos exhumados, en especial su régimen jurídico (Montero 2010) ${ }^{11}$. Respecto a esta continuada ambigüedad sobre su estatuto legal, ya en 2006 la creciente sospecha de muchas familiares y asociaciones sobre la falta de contundencia de la futura Ley de Memoria Histórica, y sobre el descarte político de la anulación de los juicios y las sentencias a muerte de los fusilados, entre otros aspectos, derivaron en denuncias por desapariciones ante el Juzgado número 5 de la Audiencia Nacional. Efectivamente, en la redacción final de la ley de 2007, algunos de los tribunales, condenas y sanciones que proporcionaron el armazón jurídico de la represión durante la guerra y la dictadura fueron declarados ilegítimos, aunque no ilegales ${ }^{12}$.

Apenas unos meses después, en el polémico auto de Garzón de diciembre de 2008, los cuerpos enterrados en fosas - categorizados en el marco de desapariciones forzadas y, por lo tanto, como crimenes de lesa humanidad permanentes e imprescriptibles - se convirtieron en el eje central de su intento de traducción del derecho penal internacional hacia el caso de la Guerra Civil

10 Véase, por ejemplo, la plasmación de esta interpretación en el recurso interpuesto por el Fiscal Jefe de la Audiencia Nacional, Javier-Alberto Zaragoza (2008, p. 22ss.), al conocido auto de Garzón sobre los crímenes del franquismo (2008).

11 El protocolo nacional, impulsado por el Ministerio de la Presidencia en cumplimiento de artículo 12.1 de la Ley 52/2007, ha sido publicado en el BOE el 27 de septiembre de 2011, más de diez años después del inicio de este ciclo de exhumaciones.

12 BOE núm. 310, de 27 de diciembre de 2007, p. 53411. 
y la dictadura. La propuesta de Garzón de buscar una ruta transnacional para amparar jurídicamente a los fusilados de las fosas comunes quedó paralizada primero en la audiencia Nacional y luego en el Tribunal Supremo. Pero independientemente de su descarrilamiento judicial, el auto de Garzón ha desencadenado un proceso simbólico y político que algunos autores denominan vida social de los derechos, con lo que se refieren a «las dimensiones performativas de los derechos humanos, la dinámica de la movilización social, y los cambios de actitud de los grupos de élite y no elitistas hacia los conceptos de "derechos" y "justicia" tanto dentro como fuera del sistema legal» (Wilson 2006, 77). El colapso interpretativo de los fusilados en la figura errante y expansiva de los desaparecidos, aun en ausencia de un anclaje legal, ha tenido un gran éxito en muchas de las asociaciones, se ha convertido en sentido común a la hora de conceptualizar a los fusilados, y coloca provisionalmente a las fosas comunes y los cadáveres que contienen en una familia transnacional de víctimas cuya casuística y prestigio está en expansión ${ }^{13}$.

Manuel Castells ya formuló hace dos décadas que «las nuevas tecnologías de la información están transformando la forma en la que producimos, consumimos, organizamos, vivimos y morimos» (2000, 15). Los medios, fundamentalmente la televisión, pero cada vez más Internet y las redes sociales, saturan nuestras vidas y condicionan profundamente nuestra experiencia del mundo. En palabras de Fiske, «en una hora de televisión cada uno de nosotros probablemente experimenta más imágenes que cualquier miembro de una sociedad no industrial experimentaría en toda su vida. La diferencia cuantitativa es tal que se convierte en categórica; no sólo experimentamos más imágenes, sino que se produce en nuestras vidas una relación totalmente distinta entre las imágenes y el resto de los órdenes de la experiencia» (1991, 58). Es por lo ineludible que otro espacio fundamental de proyección de los cuerpos exhumados en la sociedad contemporánea se refiera a su vida mediática, es decir, su recorrido más o menos espectacularizado en la sociedad de la información y el conocimiento, desde los medios más tradicionales hasta las nuevas tecnologías digitales de la comunicación y el ciberespacio. Como corresponde al vértigo y volatilidad de la sociedad de la información y el conocimiento, este viaje de los cuerpos exhumados a través de los medios y la nuevas tecnologías digitales ha conocido picos y valles, momentos de gran intensidad y de menor visibilidad, épocas de novedad o incluso sorpresa junto a otras de saturación o sobrecarga — visual, comunicativa, empática- (Ignatieff 1998). También han estado expuestos a transformaciones informativas, ideológicas e iconográficas atribuibles a la diversidad de plataformas y lenguajes tecnológicos en los que se inscriben y a su evolución acelerada, a las

13 Sobre los detalles de este proceso, y el cuestionamiento que no pocos intelectuales e investigadores hacen de esta importación de la figura de los desaparecidos para el caso español, veáse Ferrándiz 2010. 
líneas editoriales de los diferentes medios, y a su engranaje paulatino con imágenes transnacionalizadas, emitidas y consumidas casi diariamente, no sólo de violencias y violaciones de los derechos humanos, sino más específicamente de exhumaciones semejantes en otros lugares del mundo.

Así, el despliegue de las fosas, de los cuerpos que contienen y de las distintas modalidades de su entrada en la modernidad tardía por los espacios y redes de la información contemporáneos, se ha hecho cada vez más complejo y multidimensional, y se ha articulado necesariamente con formas emergentes de del plasmación, circulación y consumo tecnológico del trauma en un mercado globalizado de imágenes del terror, del sufrimiento y del pasado traumático (Ferrándiz y Baer 2008). Como ejemplo del proceso de entrelazamiento de los subterrados con estos circuitos trasnacionales, mencionaré muy brevemente el significado iconográfico de su transformación de fusilados a desaparecidos, derivado del auto de Garzón de 2008 ya discutido (Ferrándiz 2010). Como señala el escritor y dramaturgo chileno Ariel Dorfman, las imágenes de los desaparecidos son ya «imágenes enormemente extendidas de la tragedia y también de la entereza, habiéndose incorporado a nuestro imaginario (planetario) de manera no menos eficaz que las ubicuas marcas y logotipos comerciales, que sin embargo transmiten un mensaje muy diferente» (2006). Dada su fuerza iconográfica y su potencial de transgresión visual, como apunta este autor, representan la respuesta más adecuada a las desapariciones, en cuanto que subvierten las políticas de invisibilización de las víctimas. Y lo hacen además satisfaciendo las necesidades de los medios de comunicación contemporáneos «con extrema eficacia y con una fuerza poética extraordinaria» (Ibid.; Ferrándiz y Baer 2008). La llegada de estas ahora prestigiosas iconografías a España son cruciales en las nuevas formas de visibilización de los subterrados en las propias exhumaciones, en actos de entrega de restos o de dignificación en muchos puntos del país, y les proporcionan una extraordinaria eficacia comunicativa y un anclaje simbólico imposible de anticipar hace unos años en los circuitos transnacionales de la información y de la solidaridad.

Finalmente, dado el perfil técnico de las exhumaciones contemporáneas, es especialmente importante su vida científica, que se da en múltiples dimensiones. Ya sea en los protocolos de excavación y documentación que inscriben en los cadáveres en el presente, o su paso por los laboratorios, su plasmación en informes forenses, su reflejo en proyectos de investigación, libros y artículos o en conferencias y jornadas de corte académico, que incluye desde aproximaciones historiográficas a otras filosóficas, antropológicas, sociológicas, psicológicas, como es el caso de este artículo. Dentro de este proceso de inscripción biopolítica - en su variante necropolítica - de los cadáveres (Foucault 1977; Hardt y Negri 2002; Mbembe 2003), la manifestación forense de la vida científica de los cadáveres subterrados es muy relevante. Por un lado, las excavaciones de las fosas comunes son coordinadas por arqueólogos 
y médicos forenses - con la presencia de antropólogos, psicólogos y otros especialistas en el entorno de la excavación-, y están orientadas, en ausencia de tutela judicial, al establecimiento de cadenas de custodia y a la recuperación y documentación de evidencias - inscritas en la disposición de los cuerpos, en cada uno de los cadáveres y en los objetos que los acompañan, desde objetos personales hasta casquillos de bala (Crossland 2009) — de los sucesos que originaron el enterramiento, especialmente el momento de la muerte pero también de otros aspectos como la clase social, el género, la edad, la clase social o las secuelas de malos tratos o torturas perimórtem. El proceso de desvelamiento lento y sistemático de las fosas se produce en el ritmo marcado por las pautas científicas que organizan la excavación. Las escenografías de visualización de los cadáveres, la interpretación de los osarios, y las formas de reparación y duelo familiar y político tienen lugar bajo el amparo de estas mismas tecnologías del conocimiento. Desde 2006 en adelante, la aparición de la posibilidad de identificaciones individualizadas mediante análisis de ADN en algunos de los casos - posibilitada por la financiación prevista por el Ministerio de la Presidencia para ayudas a las víctimas - han transformado drásticamente las expectativas de muchos familiares de fusilados sobre la posibilidad de recuperar cadáveres concretos, más allá del prestigio inicial de las comunidades de muerte - si murieron juntos y fueron arrojados juntos a la fosa, que se entierren juntos - que predominaba en la sensibilidad de las asociaciones de víctimas en los primeros años (Ríos, Casado y Puente 2010). Este proceso de individualización identitaria de los cadáveres exhumados - que afecta directamente sólo a una minoría de ellos, pero lo hace cada vez más a todo el conjunto como potencial de acción y dignificación-, unido al creciente prestigio contemporáneo de las ciencias forenses como herramienta básica de reparación en casos de violación de los derechos humanos, está provocando el despliegue de una forma emergente de ciudadanía transnacional biológica para los cadáveres. Esta nueva ciudadanía para los subterrados, relacionada con formas de victimización determinadas genéticamente, vinculadas a su vez a la expansión de ciertos discursos y prácticas de los derechos humanos, permite tejer analogías y marcar diferencias con otras experiencias históricas de crímenes contra la humanidad de la misma especie simbólica y legal en otros lugares del mundo, todas ellas parte del creciente catálogo transnacional de la barbarie (Ferrándiz 2010; Wagner 2009; Rose 2007; Fox 2005, 191-194; Golob 2002).

Con esta autopsia social de algunos de los itinerarios corpóreos contemporáneos de los cadáveres de fusilados y ejecutados que están saliendo a la luz pública en la última década, a pesar de la necesaria brevedad en el tratamiento de sus diferentes manifestaciones, he querido subrayar el impacto profundo y diversificado que las exhumaciones de las fosas comunes derivadas de la represión de la retaguardia franquista están teniendo en la sociedad española actual, y también más allá de las fronteras nacionales. Tras este re- 
corrido, es posible argumentar que las exhumaciones de fosas están siendo muy relevantes en el desaprendizaje del franquismo y de su legado militarista. Este proceso de desarme o desmantelamiento significativo de la estructura represiva del franquismo y de su arquitectura de propaganda está forzando al país a descender hasta los detalles casi microscópicos de las heridas en las que fue inscrita en los cuerpos ejecutados, para luego confrontar críticamente su recorrido diagnóstico por la sociedad española contemporánea, desde su repertorio de apariciones mediáticas a las leyes o procedimientos judiciales presentes y ausentes, desde el silencio de décadas al ciberespacio, desde los debates y controversias políticas hasta las conmemoraciones populares, desde los libros o artículos académicos al arte conceptual, desde su perfil genético hasta su plasmación digital. Así de diversificado, posiblemente abrumador, y sin duda inquietante y excepcional, está siendo el retorno de los subterrados a la vida pública española de principios del siglo XXI.

\section{BIBLIOGRAFÍA}

Agamben, Giorgio (2004): Estado de excepción. Homo Sacer II, 1, trad. de A. Gimeno, Pre-Textos, Valencia.

Aguilar, Paloma (2008): Políticas de la memoria y memorias de la política, Alianza, Madrid.

BENJAMIN, Walter (2005): Tesis sobre la historia y otros fragmentos, trad. y presentación de B. Echeverría, Contrahistorias, México.

Box, Zira (2010): España, año cero, Alianza, Madrid.

CASANOvA, Julián (1999): «Del terror "caliente" al terror "legal”», en Santos Juliá (coord.), Víctimas de la Guerra Civil, Temas de Hoy, Madrid, 159-177.

CASANOva, Julián (2002): «Una dictadura de cuarenta años», en CASANOva et al., Morir, matar, sobrevivir: La violencia en la dictadura de Franco, Crítica, Barcelona, 3-50.

CASTELls, Manuel (2000): La era de la información, vol. 1, Alianza, Madrid.

Crossland, Zoe (2009): «Acts of estrangement: The making of self and other through exhumation», Archaeological Dialogues, 16(1), 102-125.

Dorfman, Ariel (2006): «The Missing and Photography: The Uses and Misuses of Globalization», en Jack SANTINo (ed.), Spontaneous Shrines and the Public Memorialization of Death, Palgrave Macmillan, Nueva York, 255-260.

Fassin, Didier y ReChTMAn, Richard (2009): The Empire of Trauma: An Inquiry into the Condition of Victimhood, Princeton University Press Princeton.

FERRÁnDIZ, Francisco (2005): «La memoria de los vencidos de la Guerra Civil: El impacto de las exhumaciones de fosas en la España contemporánea», en José María VALCUENDE y Susana NAROTZKY (eds.), Las políticas de la memoria en los sistemas democráticos: Poder, política y mercado, ASANA, Sevilla, 109-32.

FERRÁndIZ, Francisco (2006): «The Return of Civil War Ghosts: The Ethnography of Exhumations in Contemporary Spain», Anthropology Today, 22 (3), 7-12.

FERRÁNDIZ, Francisco (2009): «Fosas comunes, paisajes del terror», Revista de Dialectología y Tradiciones Populares, LXIV (1), 61-94. 
FERRÁNDIZ, Francisco (2010): «De las fosas comunes a los derechos humanos: El descubrimiento de las desapariciones forzadas en la España contemporánea», Revista de Antropología Social, 19, 161-189.

FERrÁndiz, Francisco y BAER, Alejandro (2008): «Digital Memory: The Visual Recording of Mass Grave Exhumations in Contemporary Spain», Forum Qualitative Sozialforschung/Forum: Qualitative Social Research [Revista on-line], 9 (3): Art. 35.

FISKE, John (1987): Television Culture, Routledge, Nueva York.

FoucAult, Michel (1997): La voluntad de saber, Historia de la sexualidad, vol. 1, México D.F., Siglo XXI.

Fox, Jonathan (2005): «Unpacking “Transnational Citizenship”», Annual Review of Political Science, 8, 171-201.

Gaos, José (1953): En torno a la filosofía mexicana, México D.F., Porrúa.

GARzón, Baltasar (2008): Auto, Diligencias previas (proc. abreviado) 399/2006V (16-10-2008). Juzgado Central de Instrucción n. ${ }^{\circ}$ 5, Audiencia Nacional, Madrid.

GonzÁlez Ruibal, Alfredo (2007): «Making Things Public: Archaeologies of the Spanish Civil War», Public Archaeology, 6 (4), 203-226.

Gordon, Avery F. (1997): Ghostly Matters: Haunting and the Sociological Imagination, Mineápolis, University of Minnesota Press.

GoloB, Stephanie (2002): "“Forced to Be Free": Globalized Justice, Pacted Democracy, and the Pinochet Case», Democratization, 9 (2), 21-42.

Hacking, Ian (1996): «Memory Sciences, Memory Politics», en Michael LAMBeK y Paul Antze (eds.), Tense Past: Cultural Essays in Trauma and Memory, Routledge, Nueva York.

HARDT, Michael y Negri, Antonio (2002): Imperio, Paidós, Barcelona.

Hirsh, Marianne (2008): «The Generation of Postmemory», Poetics Today, 29 (1), 103-128.

IGNATIEFF, Michael (1998): El honor del guerrero: Guerra étnica y conciencia moderna, Taurus, Madrid.

INIESTA, M. (2009): «Patrimonio, ágora, ciudadanía: Lugares para negociar memorias productivas», en El Estado y la memoria: Gobiernos y ciudadanos frente a los traumas de la historia, ed. por Ricard Vinyes, Barcelona, RBA, 467-498.

JuLIÁ, Santos (1999): «Prólogo: De "guerra contra el invasor" a "guerra fratricida"», en Santos Juliá (coord.), Víctimas de la Guerra Civil, Temas de Hoy, Madrid.

JuRIS, Jeffrey (2008): Networking Futures: The Movements Against Corporate Globalization, Duke University Press, Durham.

KLINEBERG, Eric (2002): Heat Wave: A Social Autopsy os Disaster in Chicago, University of Chicago Press, Chicago.

Marcus, G. E. (1995): «Ethnography in/of the World System: The Emergence of Multi-Sited Ethnography», Annual Review of Anthropology 24: 95-117.

Mate, Reyes (2009): Medianoche en la historia, Trotta, Madrid.

Mbembe, Achille (2003): «Necropolitics», Public Culture, 15(1), 11-40.

Molinero, Carme (2005): La captación de las masas: Política social y propaganda en el régimen franquista, Cátedra, Madrid.

MonClús, Antonio (1989): "Gaos y el significado del "transterrado"», en José Luis ABELlán y Antonio Monclús (coords.), El pensamiento español contemporáneo y la idea de América II: El pensamiento del exilio, Anthropos, Barcelona. 
Montero, Juan (2010): «Exhumando el legado material de la represión franquista: De la percepción social a la encrucijada jurídica y patrimonial», en J. ALMANSA SÁNCHEZ (ed.), Recorriendo la Memoria, BAR IS, Oxford.

NORA, Pierre (1989): «Between Memory and History: Les Lieux», Representations, $26,7-25$.

Olesen, Thomas (2005): International Zapatismo. Zed Books, Londres.

Preston, Paul (2011): El Holocausto español: Odio y exterminio en la Guerra Civil y después, Debate, Barcelona.

Ríos, Luis; CASADO, José Ignacio y PuEnTE, Jorge (2010): «Identification process in mass graves from the Spanish Civil War I», Forensic Science International, 199, e27-e36.

RobBen, Antonius C. G. M. (2000): «State Terror in the Netherworld: Disappearance and Reburial in Argentina», en J. A. SluKA (ed.), Death Squad: The Anthropology of State Terror, University of Pennsylvania Press, Filadelfia, 91-113.

Rodrigo, J. (2008): Hasta la raíz: Violencia durante la Guerra Civil y la dictadura franquista, Alianza, Madrid.

Rose, Nikolas (2007): The Politics of Life Itself: Biomedicine, Power, and Subjectivity in the Twenty-First Century, Princeton University Press, Woodstock.

TAussig, Michael (1992): The Nervous System, Routledge, Nueva York.

Verdery, Katherine (1999): The Political Lives of Dead Bodies, Columbia University Press, Nueva York.

WAGNER, Sarah (2008): To Know Where He Lies: DNA Technology and the Search for Srebrenica's Missing, Berkeley, University of California Press.

WATTS, Michael (1992): «Capitalisms, Crisis and Cultures I. Notes Towards a Totality of Fragments», en Allan PRED y Michael WATTS, Reworking modernity: Capitalisims and Symbolic Discontent, Rutgers University Press New Brunswick (New Jersey), 1-19.

WiLSON, Richard A. (2006) "Afterword to "Anthropology and Human Rights in a New Key”: The Social Life of Human Rights», American Anthropologist, 108 (1), 77-83.

WINTER, Jay (1995): Sites of memory, sites of mourning: the Great War in European cultural history, Cambridge University Press, Cambridge.

ZAMORA, José Antonio (2008): «Dialéctica mesiánica: Tiempo e interrupción en Walter Benjamin», en Gabriel Amengual i Coll, Mateu Cabot Ramis y Juan Luis VERMAL BERETTA (coords.), Ruptura de la tradición: estudios sobre Walter Benjamin y Martin Heidegger, Trotta, Madrid, 83-137.

ZARAGOZA, Javier-Alberto (2008): Recurso a las diligencias previas 399/2006 del Juzgado Central de Instrucción n. 5 (actualmente sumario 53/08), Fiscalía de la Audiencia Nacional, Madrid. 